\title{
Analysis of genetic diversity of gac [Momordica cochinchinensis (Lour.) Spreng] in Southern Vietnam using fruit-morphological and microsatellite markers
}

\author{
Pham Duc Toan ${ }^{1}$, Huynh Van Biet ${ }^{1}$, Vo Thi Thuy Hue ${ }^{1}$, Huynh Dang Sang ${ }^{1}$, Bui Minh $\operatorname{Tri}^{1}$, Bui Cach \\ Tuyen $^{2}$
}

\author{
${ }^{1}$ Research Institute for Biotechnology and Environment, Nong Lam University, Ho Chi Minh city, Vietnam - Linh \\ Trung ward, Thu Duc district, Ho Chi Minh city, Vietnam \\ ${ }^{2}$ Faculty of Environment and Natural Resources, Nong Lam University, Ho Chi Minh city, Vietnam - Linh Trung ward, \\ Thu Duc district, Ho Chi Minh city, Vietnam
}

\section{*Corresponding author: phamductoan@hcmuaf.edu.vn}

\begin{abstract}
Sweet gourd (Momordica cochinchinesis (Lour.) Spreng) $(2 n=28)$ belongs to Cucurbitaceae family and is native to Southeast Asia as well as Vietnam. It is indigenous throughout Asia and being used as food and for medicinal purpose. The aim of this study was to estimate genetic diversity of gac accessions collected from Southern Vietnam based on 7 fruit-morphological traits and 10 SSR markers. The analysis of variance (ANOVA) revealed highly significant differences among 16 gac accessions. The gac accessions revealed difference in all fruit-morphological characters. Ten SSR primers showed high level of polymorphic fragments (100\%). A total of 52 alleles were detected and the number of alleles per locus ranged from 2 to 8 with an average of 5.2 alleles per locus. The fragment size varied from $150 \mathrm{bp}$ to $610 \mathrm{bp}$. The polymorphism information contents $(P I C)$ of markers varied from 0.27 to 0.86 with an average of 0.58 . Expected heterozygosity $\left(H_{E}\right)$ ranged from 0.11 to 0.86 with a average of 0.40 . The mean of observed heterozygosity $\left(H_{O}\right)$ was 0.64 with ranging $0.38-0.94$. Nei's genetic distance coefficient ranged between 0.0 and 1.0 and with the mean 0.79. Dendrogram based on UPGMA analysis grouped the 16 gac accessions into three main groups. Combination of fruitmorphological with molecular markers such as microsatellite markers gives a good observation of genetic diversity of gac accessions.
\end{abstract}

Keywords: Dendrogram, Gac, Polymorphism, SSR markers, Sweet gourd.

\section{Introduction}

Sweet gourd (Momordica cochinchinesis (Lour.) Spreng) (2n = 28) belongs to Cucurbitaceae family and is native to Southeast Asia as well as in Vietnam. It is indigenous throughout Asia and used as food and for medicinal purpose (Ishida et al., 2004). The genus Momordica comprises 59 species, of which 47 species were found in Africa and 12 species in Southeast Asia and Australia (Schaefer and Renner, 2010). M. cochinchinesis is popularly known as Gac in Vietnam. Gac plant is a perennial dioecious vine with 3 to 5 lobed leaves and white to ivory yellow flowers (Bharathi and John, 2013). The gac fruit is red color at ripe stage and are large with 11 to $17 \mathrm{~cm}$ in diameter, 13 to $22 \mathrm{~cm}$ in length, 0.6 to $2.7 \mathrm{~kg}$ per fruit. Gac seeds covered by red aril and are brown to blackish color depend on variety.

Gac is important for its nutrition and medicinal properties, thus this crop has been cultivated in various regions of Vietnam for commercial purpose. However, the information on gac varieties is limited. The lack of information available on genetic diversity is a barrier to improve gac varieties. Information on genetic diversity and relationship among populations is important for plant breeding programs as it helps to select the right genetic material to be used (Ganesh and Thangavelu, 1995). Presently, the insufficient genetic information regarding gac populations in Vietnam is limiting the access to useful traits present among adapted varieties of gac in Vietnam. Genetic diversity in crop species can be determined using morphological and agronomic characteristics as well as biochemical and molecular markers (Koornneef, 1990; Reiter et al., 1992; Liu, 1997). Studies on genetic diversity and interrelation analysis of $M$. cochinchinesis have been mainly based on agromorphological and physiological variation (Sanwal et al., 2007; Bootprom et al., 2015). Several of these agromorphological and physiological variation based studies have found a high genetic diversity in $M$. cochinchinesis genotypes (Sanwal et al., 2007; Bootprom et al., 2015; Wimalasiri et al., 2016). Variation of fruit morphology is common in Momordica genus, however the extent of the variation observed in $M$. cochinchinesis based on where it is grow is unknown (Bharathi and John, 2013; Wimalasiri et al., 2016). Previously, high genetic diversity of 40 Sweet gourd (M. cochinchinesis) genotypes of Northeast India was found based on agro-morphological traits (Sanwal et al., 2007). Morphological variability of eight accessions of $M$. 
cochinchinesis was studied in India (Bharathi and John, 2013). However, morphological characters have limitation since they are influenced by environmental factors and the developmental stage of the plant (Dey et al., 2006). Molecular markers overcome this limitation as they are independent of environmental conditions and show higher levels of polymorphism (Dey et al., 2006; Pham et al., 2009). Molecular markers also have been widely used in genetic diversity studies in crops. For example, molecular marker like RAPD markers have been used to access genetic diversity among sesame populations (Salazar et al., 2006; Pham et al., 2009), bitter gourd (Dey et al., 2006), spine gourd (Rasul et al., 2007; Patil et al., 2012), spiny bitter gourd or gac (Bootprom et al., 2012; Wimalasiri et al., 2016), and ISSR markers have been applied to estimate genetic variation of eggplant (Isshiki et al., 2008), Chinese yam (Zhou et al., 2008), Indian bitter gourd (Behera et al., 2008), gac (Wimalasiri et al., 2016). SSR markers also have been employed in genetic diversity of potato (Ispizua et al., 2007), garlic (Zhao et al., 2011; Jo et al., 2012), soybean (Doldi et al., 1997; Tantasawat et al., 2011), and bitter gourd (Wang et al., 2010; Guo et al., 2012). In this study, fruit-morphological and SSR markers were used for analysis of genetic diversity of gac ( $M$. cochinchinensis) accessions collected from Southern Vietnam in order to generate information for the selection of divergent genotypes for breeding and for designing effective conservation strategies for gac genetic resources in Vietnam.

\section{Results}

\section{Fruit-morphological analysis}

Total of 16 gac accessions collected from different regions were used in this study (Table 1 and Fig 1) Analysis of variance (ANOVA) revealed highly significant differences among 16 gac accessions (Table 2). The six-teen gac accessions revealed different in all of fruit-morphological characters (Fig 2, and 3). The female flower bud in some gac accessions appeared lately on the vine. In other accessions the female flower bud appeared at early, about 2.0-2.5 months after planting. The flowers color of 16 gac accessions was predominantly white with yellow to white light yellow. Leaves and fruit were varying much either in their size and shape. The fruits were harvested at maturity stage with the color turned orangey-red to dark red. Fruit weight ranged from $0.6(\mathrm{G}-\mathrm{KH})$ to $2.7 \mathrm{~kg}$ per fruit $(\mathrm{G}-\mathrm{LD})$ and fruit length was recorded ranging from $13.7(\mathrm{G}-\mathrm{KH})$ to $21.3 \mathrm{~cm}$ (G-LD). Fruit diameter was from 9.7 to $17 \mathrm{~cm}$, with the mean values of $13.8 \mathrm{~cm}$. Mesocarp thickness of 16 gac accessions was recorded ranging from 1.5 to $3.0 \mathrm{~cm}$ with an average of 2.2 $\mathrm{cm}$. Gac aril was in red color at ripe stage and it contains high amount of oil and fatty acids. Seed was varies shape and the color from brown to light-black, brown to blackish, black and dark black. Weight of aril-seed ranged from 201 to 902 gram with an average of 450.3 gram per fruit. Percentage of aril-seed was also recorded from 20.3 to $66.4 \%$ with mean value of $37.3 \%$. 10-seed weight of 16 gac accessions ranged from 21.9 to 44.4 gram (Table 2).

\section{SSR markers analysis}

Four gac accessions were used for evaluating amplification level of primers. Total of 26 SSR markers developed by Wang et al. (2010) and Gou et al. (2012) were screened for their ability to amplify polymorphic markers. Ten primers amplified distinctive fragments in the four gac accessions. Therefore, ten SSR primers were selected for PCR amplification of all samples (Table 3, Fig. 4). Total of ten SSR primers were used to estimate genetic diversity of 16 gac accessions. All of ten primers showed high level of polymorphic fragments (100\%). A total of 52 alleles were detected and the number of alleles per locus ranged from 2 for primer N6 to 8 for primer S12 with an average of 5.2 alleles per locus. The fragment size varied from $150 \mathrm{bp}$ to $610 \mathrm{bp}$. The polymorphism information contents $(P I C)$ of markers varied from 0.27 to 0.86 with an average of 0.58 . Primer N5 revealed the highest PIC of 0.86 , while primer N6 showed the lowest PIC of 0.27 (Table 3). Genetic variation among 16 gac accessions was estimated based on heterozygosity. Expected heterozygosity $\left(H_{E}\right)$ ranged from 0.11 to 0.86 with a average of 0.40 . The mean of observed heterozygosity $\left(H_{O}\right)$ was 0.64 with ranging $0.38-0.94$. The highest observed heterozygosity was in marker A47 with a value of 0.94 , while the lowest was 0.38 in marker S12 (Table 3).

The genotypes of accessions G-BP, G-TN, G-AG represented the lowest percentage of within population variation $(\% P=$ $10 \%, P I C=0.07$ ), whereas the genotypes of accessions G-LD, G-DT represented the highest percentage of within population variation $(P=70 \%, P I C=0.46$ and 0.44$)$. Furthermore, the lowest $H_{E}$ was recorded on accession G-LD $\left(H_{E}=0.66\right)$, the highest $H_{E}$ was 0.95 for accessions G-BP, GTN and G-AG. Similarly, the highest $H_{O}$ was recorded for accession G-BP, G-TN, G-AG with a value of 0.90 , and accession G-LD showed lowest $H_{O}=0.37$ value. The average variation within the studied gac accessions was $39.4 \%$ of polymorphism, 0.27 of $P I C, 0.64$ of $H_{O}$ and 0.80 of $H_{E}$ (Table 2).

Nei's genetic distance coefficient ranged between 0.0 and 1.0 with the mean value of 0.79 (Table 4, Fig. 5). Dendrogram based on UPGMA analysis grouped the 16 gac accessions into three main groups (Fig. 5), with the genetic distance coefficient ranged from 0.0 to 1.0 . Cluster I was the biggest group and included 8 accessions (G-KG, G-DT, G-CT, G-DN, G-TN, G-BP, G-LA, G-AG). Cluster II consisted of 6 accessions (G-DkN, G-GL, G-DkL, G-KH, G-NT, G-LD) and cluster III was composed of 2 accessions (G-BD, G-PY). Combinations of fruit-morphological with SSR markers, the clusters mean were characterized as the follows. Cluster II comprised accessions with the mean of traits as highest fruit weight $1.5 \mathrm{~kg}$ per fruit, weight of aril-seed (509.3 gram per fruit) and percentage of aril-seed (39.3\%). Cluster III consisted of accessions with the mean of traits as lowest fruit weight (1.2 kg per fruit), weight of aril-seed (301.2 gram per fruit), percentage of aril-seed (27.8\%), and 10-seed weight (27.0 gram). Accessions in cluster I showed that the mean of traits was $1.3 \mathrm{~kg}$ per fruit of fruit weight, weight of aril-seed (443.4 gram per fruit), percentage of aril-seed (38.1\%), and 10-seed weight (30.5 gram) (Table 2, Fig 5).

\section{Discussion}

Evaluation of genetic diversity of gac gives the breeder an opportunity to take up selection, identification of cultivars, and screening of parents in plant breeding program. By utilizing the fruit-morphological, agronomic traits could be improve productivity of gac varieties. Morphological characters of gac was reported in previous studies by Sanwal et al. (2007), Bootprom et al. (2015) and Wimalasiri et al. 
Table 1. List of six-teen gac (M. cochinchinensis) accessions used in this study

\begin{tabular}{|c|c|c|c|c|c|}
\hline ID & $\begin{array}{l}\text { Accession } \\
\text { code }\end{array}$ & Province & Region of collection & GPS & Altitude $(\mathrm{m})$ \\
\hline 1 & G-PY & Phu Yen & South Central coast region & $13.08 .36 \mathrm{~N} 109.16 .41 \mathrm{E}$ & 13 \\
\hline 2 & G-BD & Binh Dinh & South Central coast region & 13.47.01 N 109.12.53 E & 10 \\
\hline 3 & $\mathrm{G}-\mathrm{KH}$ & Khanh Hoa & South Central coast region & $12.18 .55 \mathrm{~N} 109.11 .13 \mathrm{E}$ & 38 \\
\hline 4 & G-NT & Ninh Thuan & South Central coast region & 11.34.48 N 108.39.29 E & 10 \\
\hline 5 & G-DkN & Dak Nong & Central Highlands region & $12.23 .49 \mathrm{~N} 107.34 .30 \mathrm{E}$ & 797 \\
\hline 6 & G-GL & Gia Lai & Central Highlands region & 13.38.08 N $108.06 .40 \mathrm{E}$ & 407 \\
\hline 7 & G-DkL & Dak Lak & Central Highlands region & $12.39 .38 \mathrm{~N} 108.02 .01 \mathrm{E}$ & 427 \\
\hline 8 & G-LD & Lam Dong & Central Highlands region & $11.31 .36 \mathrm{~N} 107.50 .39 \mathrm{E}$ & 758 \\
\hline 9 & G-LA & Long An & Southeast region & 10.37.09 N 106.21.55 E & 1 \\
\hline 10 & G-BP & Binh Phuoc & Southeast region & $11.32 .29 \mathrm{~N} 106.54 .57 \mathrm{E}$ & 83 \\
\hline 11 & G-TN & Tay Ninh & Southeast region & $11.02 .01 \mathrm{~N} 106.23 .11 \mathrm{E}$ & 12 \\
\hline 12 & G-DN & Dong Nai & Southeast region & $10.52 .47 \mathrm{~N} 106.26 .07 \mathrm{E}$ & 127 \\
\hline 13 & G-CT & Can Tho & Mekong River delta region & $10.08 .50 \mathrm{~N} 105.38 .25 \mathrm{E}$ & 2 \\
\hline 14 & G-DT & Dong Thap & Mekong River delta region & 10.28.53 N 105.34.47 E & 10 \\
\hline 15 & G-KG & Kien Giang & Mekong River delta region & $10.02 .00 \mathrm{~N} 105.05 .41 \mathrm{E}$ & 5 \\
\hline 16 & G-AG & An Giang & Mekong River delta region & 10.09.15 N 105.20.36 E & 4 \\
\hline
\end{tabular}

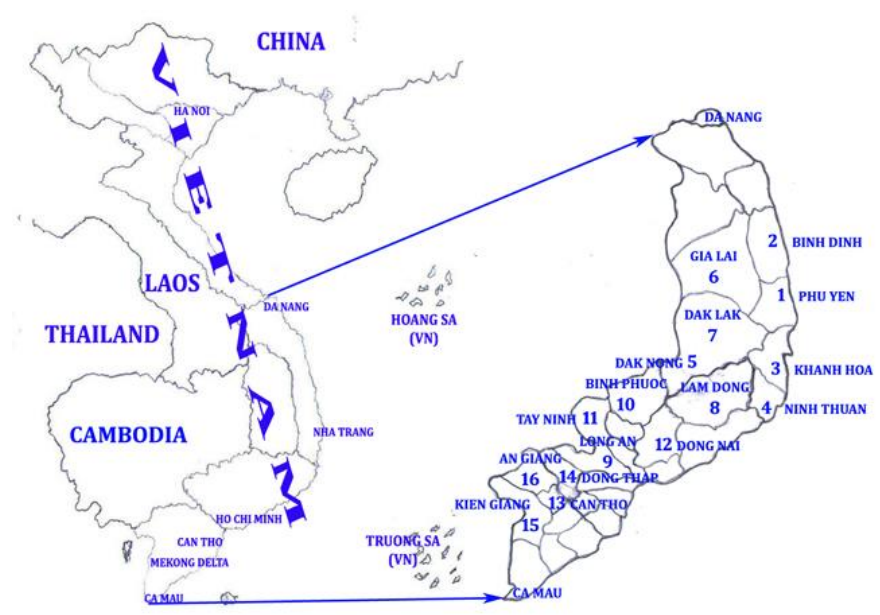

Fig 1. Geographical distributions of the $16 \mathrm{gac}$ (M. cochinchinensis) accessions used in this study. 
Table 2. Fruit-morphological and Microsatellite (SSR) characters of six-teen gac accessions collected in Southern Vietnam

\begin{tabular}{|c|c|c|c|c|c|c|c|c|c|c|c|c|c|c|c|c|c|c|c|c|}
\hline \multirow[b]{2}{*}{ ID } & \multirow[b]{2}{*}{$\begin{array}{l}\text { Accession name } \\
\text { code }\end{array}$} & \multirow{3}{*}{$\begin{array}{l}\text { Fruit weight } \\
(\mathrm{kg})\end{array}$} & \multicolumn{13}{|c|}{ Fruit-morphological characters } & \multicolumn{5}{|c|}{ Microsatellite (SSR) characters } \\
\hline & & & & $\begin{array}{l}\text { Fruit } \\
\text { length } \\
\text { (cm) }\end{array}$ & & $\begin{array}{l}\text { Fruit diameter } \\
(\mathrm{cm})\end{array}$ & & $\begin{array}{r}\text { Mesc } \\
\text { thickne }\end{array}$ & & $\begin{array}{l}\text { Weight of aril-seed } \\
\text { (gram) }\end{array}$ & & $\begin{array}{c}\begin{array}{c}\% \text { aril- } \\
\text { seed/fruit }\end{array} \\
\text { sed }\end{array}$ & & $\begin{array}{c}\begin{array}{c}\text { 10-seed } \\
\text { weight (gram) }\end{array}\end{array}$ & & No. of $P$ & $\% P$ & $P I C$ & $H_{0}$ & $H_{E}$ \\
\hline 1 & G-PY & & $d$ & 173 & cdef & & $c d$ & 30 & $a$ & 2507 & $\mathrm{i}$ & & $i$ & 263 & h & & 500 & 030 & 0.59 & 078 \\
\hline 2 & $G-B D$ & 1.1 & ef & 18.0 & cde & 12.3 & $\mathrm{e}$ & 1.5 & d & 351.7 & $\mathrm{~g}$ & 35.3 & $\mathrm{f}$ & 27.6 & $\mathrm{~g}$ & 6 & 60.0 & 0.41 & 0.49 & 0.71 \\
\hline 3 & $\mathrm{G}-\mathrm{KH}$ & 0.6 & $\mathrm{~h}$ & 13.7 & $\mathrm{~h}$ & 9.7 & g & 1.6 & d & 201.0 & $\mathbf{k}$ & 40.3 & $\mathrm{~cd}$ & 27.8 & $\mathrm{~g}$ & 3 & 30.0 & 0.33 & 0.71 & 0.80 \\
\hline 4 & G-NT & 1.4 & $\mathrm{~cd}$ & 19.3 & a & 15.0 & $\mathrm{~b}$ & 2.0 & c & 500.7 & e & 35.8 & f & 22.8 & $\mathrm{i}$ & 5 & 50.0 & 0.30 & 0.59 & 0.78 \\
\hline 5 & G-DkN & 1.5 & c & 18.7 & bcd & 14.0 & c & 3.0 & a & 600.3 & c & 39.7 & d & 21.9 & j & 6 & 60.0 & 0.43 & 0.42 & 0.68 \\
\hline 6 & $G-G L$ & 1.1 & ef & 16.0 & efg & 13.0 & de & 1.6 & d & 350.7 & $\mathrm{~g}$ & 35.3 & f & 35.3 & c & 4 & 40.0 & 0.22 & 0.73 & 0.84 \\
\hline 7 & G-DkL & 1.6 & c & 17.0 & def & 15.3 & $\mathrm{~b}$ & 2.5 & b & 501.0 & e & 31.5 & $\mathrm{~g}$ & 22.6 & i & 4 & 40.0 & 0.28 & 0.61 & 0.79 \\
\hline 8 & G-LD & 2.7 & a & 21.3 & $\mathrm{a}$ & 17.0 & a & 2.5 & b & 902.0 & a & 53.0 & b & 44.4 & a & 7 & 70.0 & 0.46 & 0.37 & 0.66 \\
\hline 9 & G-LA & 0.9 & $\mathrm{fg}$ & 14.3 & $\mathrm{gh}$ & 13.0 & de & 2.0 & c & 333.3 & $\mathrm{i}$ & 41.5 & c & 31.4 & e & 3 & 30.0 & 0.21 & 0.70 & 0.84 \\
\hline 10 & G-BP & 2.1 & b & 20.3 & $\mathrm{a}$ & 17.0 & $a$ & 2.5 & b & 700.7 & b & 31.9 & $\mathrm{~g}$ & 22.8 & $\mathrm{i}$ & 1 & 10.0 & 0.07 & 0.90 & 0.95 \\
\hline 11 & G-TN & 1.5 & $\mathrm{~cd}$ & 17.3 & cdef & 15.0 & b & 2.6 & b & 340.0 & $\mathrm{~h}$ & 24.0 & $\mathrm{~h}$ & 31.9 & de & 1 & 10.0 & 0.07 & 0.90 & 0.95 \\
\hline 12 & G-DN & 1.1 & ef & 16.3 & efg & 13.0 & de & 2.6 & $\mathrm{~b}$ & 350.0 & $\mathrm{~g}$ & 35.0 & f & 30.3 & $f$ & 2 & 20.0 & 0.14 & 0.80 & 0.89 \\
\hline 13 & $\mathrm{G}-\mathrm{CT}$ & 1.2 & e & 15.7 & fgh & 14.0 & c & 2.0 & c & 423.3 & $f$ & 38.5 & e & 26.4 & $\mathrm{~h}$ & 3 & 30.0 & 0.21 & 0.70 & 0.84 \\
\hline 14 & G-DT & 1.2 & e & 16.0 & efg & 13.3 & $\mathrm{~cd}$ & 1.6 & d & 350.0 & $\mathrm{~g}$ & 32.2 & $\mathrm{~g}$ & 32.5 & d & 7 & 70.0 & 0.44 & 0.39 & 0.67 \\
\hline 15 & G-KG & 1.6 & c & 17.7 & cdef & 15.0 & b & 2.0 & c & 550.0 & d & 35.7 & f & 42.5 & b & 5 & 50.0 & 0.35 & 0.50 & 0.74 \\
\hline \multirow[t]{3}{*}{16} & G-AG & 0.8 & $\mathrm{~g}$ & 14.7 & gh & 11.0 & $f$ & 2.0 & c & 500.0 & e & 66.4 & $\mathrm{a}$ & 26.3 & $\mathrm{~h}$ & 1 & 10.0 & 0.07 & 0.90 & 0.95 \\
\hline & Mean & 1.3 & & 17.1 & & 13.8 & & 2 & & 450.3 & & 37.3 & & 29.5 & & 3.9 & 39.4 & 0.27 & 0.64 & 0.80 \\
\hline & $P$-value & $* * *$ & & $* * *$ & & $* * *$ & & $*$ & & $* * *$ & & & & $* * *$ & & & & & & \\
\hline
\end{tabular}

Means in a column followed by same letter are not significantly different at $P$-value $\leq 0.001$. No. of $P$ : Number of polymorphism.

\%P: Percentage of polymorphism; $H_{\varepsilon}$ and $H_{0}:$ Expected heterozygosity and observed heterozygosity, respectively

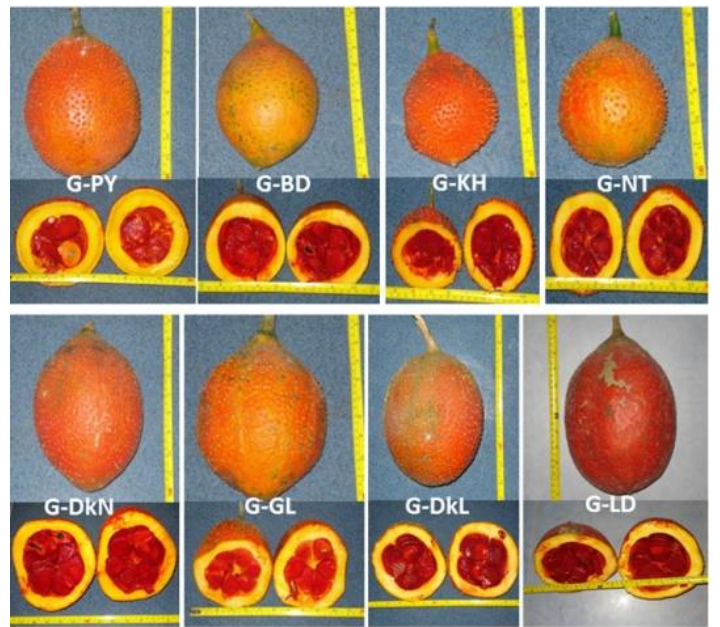

Fig 2. Gac accessions collected form South Central coast and Central Highlands region 


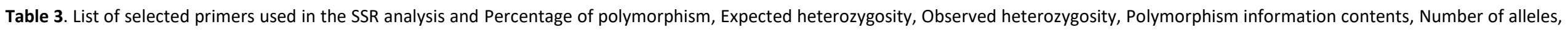
Molecular size range

\begin{tabular}{|c|c|c|c|c|c|c|c|c|c|}
\hline $\begin{array}{l}\text { Primer } \\
\text { name }\end{array}$ & GenBank accession No. & Sequence & $T_{m}$ & $N_{a}$ & $\% P$ & MSR (bp) & $H_{0}$ & $H_{E}$ & PIC \\
\hline N5 & GU166218 & $\begin{array}{l}\text { F: CGTCGCTCTCACAAGAGATAAG } \\
\text { R: TTTGGTGGAAATCCCCTATT }\end{array}$ & 59 & 3 & 100 & $150-220$ & 0.88 & 0.46 & 0.86 \\
\hline N6 & GQ338437 & $\begin{array}{l}\text { F: GGGAATTCTCAAAGAGCCAGA } \\
\text { R: TGGCACACTCTGCATGAAAT }\end{array}$ & 57 & 2 & 100 & $150-180$ & 0.85 & 0.86 & 0.27 \\
\hline N12 & GU166220 & $\begin{array}{l}\text { F: CAGAGGGGTGGTTCCTCTTT } \\
\text { R: CCACATGGATGATCGAGAGA }\end{array}$ & 59 & 6 & 100 & $180-200$ & 0.43 & 0.30 & 0.40 \\
\hline A47 & GQ995492 & $\begin{array}{l}\text { F: TGGAATGGCAACTACACG } \\
\text { R: GGGGAGGCTGAAAGACTA }\end{array}$ & 55 & 5 & 100 & $550-610$ & 0.94 & 0.54 & 0.97 \\
\hline C24 & GQ995499 & $\begin{array}{l}\text { F: TGGCTCAGTATCGCAAGTAT } \\
\text { R: GAGGAGGAAGTTTGACCTATGA }\end{array}$ & 55 & 6 & 100 & $280-380$ & 0.81 & 0.32 & 0.36 \\
\hline S13 & GQ338440 & $\begin{array}{l}\text { F: TTGGTTGTGGTGCTGAGTTC } \\
\text { R: GATGTAGGGGTTGGGTGAT }\end{array}$ & 57 & 7 & 100 & $290-400$ & 0.39 & 0.22 & 0.82 \\
\hline S15 & GQ338441 & $\begin{array}{l}\text { F: GGGTAGTGGAATGATGGGTT } \\
\text { R: TAGTGTTTTCGTGAGGGAGG }\end{array}$ & 57 & 4 & 100 & $220-260$ & 0.88 & 0.82 & 0.41 \\
\hline S20 & GU166222 & $\begin{array}{l}\text { F: CCCCTTCTAATCACAACCAA } \\
\text { R: GGCCTAATTTCTGCCCTTT }\end{array}$ & 58 & 5 & 100 & $450-520$ & 0.50 & 0.19 & 0.51 \\
\hline S24 & GQ338443 & $\begin{array}{l}\text { F: GCTCTGCGTTTCATTCTTCA } \\
\text { R: TGAACCCTCAGACTCAAACTC }\end{array}$ & 60 & 6 & 100 & $210-290$ & 0.39 & 0.11 & 0.39 \\
\hline S12 & GQ338439 & $\begin{array}{l}\text { F: GACATCCTTCTTGCCTCTTACA } \\
\text { R: GAAACGGAACGAAACCTCA }\end{array}$ & 57 & 8 & 100 & $380-420$ & 0.38 & 0.20 & 0.79 \\
\hline $\begin{array}{l}\text { Mean } \\
\text { Total }\end{array}$ & & & & $\begin{array}{l}5.20 \\
52\end{array}$ & 100 & $150-610$ & 0.64 & 0.40 & 0.58 \\
\hline
\end{tabular}

\%P: Percentage of polymorphism; $H_{\varepsilon}$ and $H_{H_{0}}:$ Expected heterozyyosity and observed heterozygosity, respectively.
PIC: Polymorphism information contents; $\mathrm{N}_{a}$ : Number of alleles; MSR: Molecular size range (bp); $T_{m}$ : annealing temperature.

Table 4. Nei's original measures of genetic distance among the six-teen gac accessions collected in Southern Vietnam

\begin{tabular}{|c|c|c|c|c|c|c|c|c|c|c|c|c|c|c|c|c|}
\hline Accession & G-PY & G-BD & G-KH & G-NT & G-DkN & G-GL & G-DkL & G-LD & G-LA & G-BP & G-TN & G-DN & G-CT & G-DT & G-KG & G-AG \\
\hline $\begin{array}{ll}\text { G-PY } \\
\end{array}$ & ---- & & & & & & & & & & & & & & & \\
\hline G-BD & 0.36 & ---- & & & & & & & & & & & & & & \\
\hline G-KH & 0.90 & 0.78 & --- & & & & & & & & & & & & & \\
\hline G-NT & 0.68 & 0.54 & 0.59 & --- & & & & & & & & & & & & \\
\hline G-DkN & 0.79 & 0.75 & 0.75 & 0.60 & ---- & & & & & & & & & & & \\
\hline G-GL & 0.60 & 0.81 & 0.81 & 0.71 & 0.36 & ---- & & & & & & & & & & \\
\hline G-DkL & 0.50 & 0.82 & 1.39 & 1.04 & 0.61 & 0.71 & ---- & & & & & & & & & \\
\hline G-LD & 0.70 & 0.71 & 1.34 & 1.04 & 1.31 & 1.18 & 0.80 & --- & & & & & & & & \\
\hline G-LA & 0.71 & 0.80 & 1.03 & 0.79 & 0.41 & 0.35 & 0.71 & 1.27 & ---- & & & & & & & \\
\hline G-BP & 0.55 & 0.71 & 0.67 & 0.78 & 0.95 & 0.50 & 0.76 & 1.22 & 0.58 & ---- & & & & & & \\
\hline G-TN & 0.98 & 0.79 & 1.21 & 1.07 & 0.89 & 0.54 & 1.13 & 1.46 & 0.75 & 0.86 & ---- & & & & & \\
\hline G-DN & 1.21 & 0.97 & 1.07 & 1.05 & 0.56 & 0.47 & 1.42 & 2.21 & 0.66 & 1.12 & 0.52 & ---- & & & & \\
\hline G-CT & 0.65 & 0.61 & 1.03 & 0.72 & 0.41 & 0.31 & 0.77 & 1.16 & 0.15 & 0.49 & 0.53 & 0.46 & ---- & & & \\
\hline G-DT & 0.34 & 0.43 & 1.25 & 0.92 & 0.80 & 0.66 & 0.66 & 0.71 & 0.87 & 0.71 & 0.65 & 0.82 & 0.72 & ---- & & \\
\hline G-KG & 0.33 & 0.14 & 0.87 & 0.54 & 0.69 & 0.76 & 0.85 & 0.67 & 0.75 & 0.74 & 0.88 & 1.09 & 0.68 & 0.42 & ---- & \\
\hline G-AG & 0.90 & 0.85 & 1.73 & 1.07 & 0.97 & 0.82 & 1.23 & 0.79 & 1.09 & 1.15 & 0.75 & 0.61 & 0.69 & 0.65 & 0.88 & ---- \\
\hline Mean & 0.68 & 0.69 & 1.06 & 0.86 & 0.72 & 0.63 & 0.92 & 1.19 & 0.69 & 0.85 & 0.66 & 0.75 & 0.70 & 0.53 & 0.88 & $0.79^{a}$ \\
\hline
\end{tabular}

Mean of values in row. 


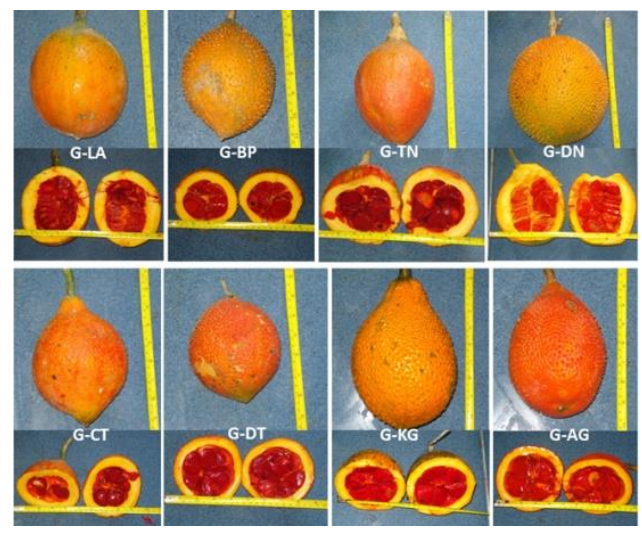

Fig 3. Gac accessions collected from Southeast and Mekong River delta region

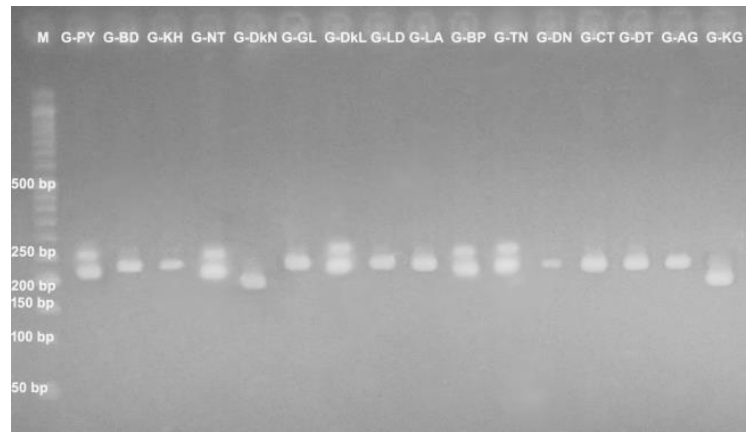

Fig 4. PCR-SSR analysis of 16 gac accessions with primer S24; M: the $50 \mathrm{bp}$ DNA ladder (NEB) ranging from $50 \mathrm{bp}$ to $1.35 \mathrm{~kb}$

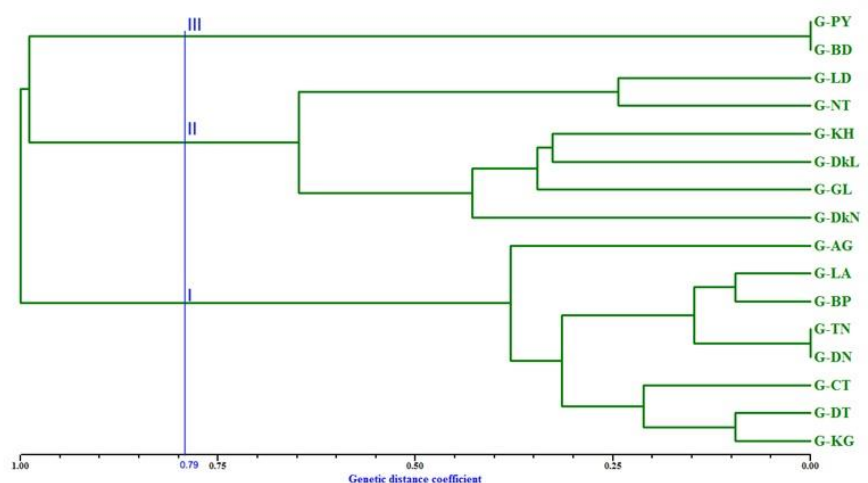

Fig 5. Dendrogram generated using UPGMA cluster analysis based on genetic diversity of 16 gac accessions

(2016) that showed a high genetic diversity in $M$. cochinchinensis. In this present study, fruit-morphological characters revealed high significant differences among 16 gac accessions, with high confidence interval at $P \leq 0.001$. Fruit-morphological characters revealed a widely variation among 16 gac accessions (Table 2). The results were in agreement with previous observations of Bootprom et al. (2015) and Wimalasiri et al. (2016) that reported widely variation among gac accessions in Thailand and Vietnam.

Microsatellite markers were also used in this study to evaluate the extent of genetic variation among gac accessions. In recent years, SSR have become one of the most widely used to characterize and evaluate genetic diversity in plant species because of more advantageous over many other markers, which are highly polymorphic, highly abundant, genetically co-dominant, and analytically simple (He et al., 2003; Miah et al., 2013). It was developed to analyse the degree of genetic diversity in $M$. charantia (Wang et al., 2010; Guo et al., 2012). The present study, ten SSR markers found high genetic diversity among 16 gac accessions and were able to discriminate between the different gac genotypes. Powell et al. (1996) reported that SSR markers give good discrimination between closely related individuals in some case even, when only a few loci were applied. High level of genetic diversity was observed among the 16 gac accessions as revealed by the high number of alleles observed $\left(N_{a}=5.2\right)$ and polymorphism information contents $(P I C=0.58)$. An estimate of the amount of heterogosity can be used as a general indicator of the amount of genetic variability in gac accession. The high observed heterogostity $\left(H_{O}=0.64\right)$ was recorded among gac accessions. A high genetic diversity in gac was reported by 
Bootprom et al. (2012) and Wimalasiri et al. (2016) using RAPD and ISSR markers. Interestingly, the results from this study, SSR markers showed higher genetic diversity than other previous studies in gac. It could be explained that the use of different methods could give different results on the level of genetic diversity (Powell et al., 1996).

Cluster results showed that most of the gac accessions had seemed to be correlated with their geographical origins. Accessions from the same geographical region were found to have a close genetic relationship, group III consisted of accession G-PY and G-BD from South Central coast region (Fig. 5). Most of accessions in group I and group II consisted of gac accessions from close regions. For example, group I composed of accessions from Southeast and Mekong River delta regions. And group II consisted of accessions from South Central coast and Central Highlands regions. Although a high genetic diversity exist between different gac accessions from various geographical locations, however it was found that some accessions situated geographically different region grouped together in the same group. For example, accession G-KH (South Central coast region) and GDkL (Central Highlands region) in cluster II (Fig. 5). The gac accessions were not defined groups according to geographical origins probably due to exchange of gac genotypes between farmers across provincial borders. A close relation of gac accessions in different regions may be a result of people to different regions carrying gac seeds for cultivation in their new residential sites. Stankiewicz et al. (2001) also reported that the human factor has previously been shown to be responsible for the lack of correlation between genetic and geographical distance in some cases.

\section{Materials and methods}

\section{Measurement of fruit-morphological traits}

The experiment was carried out at experimental field of Nong Lam University in Ho Chi Minh city, Vietnam $\left(10^{\circ} 52^{\prime} 11 \mathrm{~N}, 106^{\circ} 47^{\prime} 12 \mathrm{E}\right)$, where the annual temperature fluctuates between $25^{\circ} \mathrm{C}$ and $35^{\circ} \mathrm{C}$ and mean annual rainfall measures up to $2,000 \mathrm{~mm}$. Six-teen $M$. cochinchinesis accessions collected from various provinces of four regions in Southern Vietnam were used in this study (Table 1, Fig. 1). The codes for accessions used in this study correspond to the initials of the name of their collection sites. The filed layout was a Randomized Complete Block Design with three replications, 10 plants per accession. The seed were sown manual by hand in plastic pots and seedling of 4 weeks old was transplanted in the experimental farm. Spacing was $3 \mathrm{~m}$ between rows and $2 \mathrm{~m}$ between plants. A basal fertilizing of earth-worm compost (about 2 ton/ha) and application of $90 \mathrm{~N}-60 \mathrm{P}-90 \mathrm{~K} \mathrm{~kg} \mathrm{ha}^{-1}$ per year was made. Plants were growth on trellis, irrigated during the whole cultivation period and pesticides, fungicides were also applied when appropriated. The fruits were harvested at maturity stage with the color turned orangey-red to dark red. Morphology of fruit for all gac accessions was characterized by seven fruitmorphological traits on five randomly selected plants per accession. These traits were measured such as (1) fruit weight $(\mathrm{kg}),(2)$ fruit length $(\mathrm{cm}),(3)$ fruit diameter $(\mathrm{cm}),(4)$ mesocarp thickness $(\mathrm{cm}),(5)$ weight of aril-seed/fruit (gram), (6) $\%$ aril-seed/fruit, (7) 10-seed weight (gram). Minitab statistical package (ver.16) was used for analysis of variance (ANOVA).

\section{DNA extraction for microsatellite markers}

The six-teen gac accessions (Table 1, Fig. 1) used for fruitmorphological study were further analyzed using microsatellite (SSR) molecular maker technique. Five plants from each accession were sampled for DNA extraction. DNA was extracted from young leaves of each plant using a protocol described in Warwick and Gugel (2003) with minor modification, as described in Pham et al. (2009)

\section{SSR assay}

Total of 26 SSR markers developed by Wang et al. (2010) and Guo et al. (2012) were used for screening polymorphic markers which these microsatellite markers were suggested their potential usefulness for application in genetic diversity of Momordica species and other species in the Cucurbitaceae family (Wang et al., 2010; Guo et al., 2012). Each PCR reaction in a volume $25 \mu \mathrm{l}$ contained about 50ng genomic DNA, $0.5 \mu \mathrm{M}$ SSR forward primer, $0.5 \mu \mathrm{M}$ SSR reverse primer, $1 X$ PCR Master mix (MyTaq Mix - Bioline) and distilled water. The PCR reaction was carried out using the Gene-Amp PCR system 9700 (Applied Biosystems) in following thermocycling condition 1 cycle of $95^{\circ} \mathrm{C}$ for $5 \mathrm{~min}$, followed by 35 cycles of $95^{\circ} \mathrm{C}$ for $1 \mathrm{~min}, 55-60^{\circ} \mathrm{C}$ for $1 \mathrm{~min}$, $72{ }^{\circ} \mathrm{C}$ for $30 \mathrm{~s}$ and a final extension step of $72 \mathrm{~min}$ at $5^{\circ} \mathrm{C}$. The annealing temperature was changed based on $\mathrm{Tm}$ values of each SSR primer pairs. The SSR fragments were separated on $2 \%$ agarose gel in 1 X TAE (40 mM Tris-acetate, $\mathrm{pH} 8.0,1 \mathrm{mM}$ EDTA) buffer at 80 volt and $200 \mathrm{~mA}$ for $1 \mathrm{~h}$. The $50 \mathrm{bp}$ DNA ladder from New England Biolabs (NEB) ranging from $50 \mathrm{bp}$ to $1.35 \mathrm{~kb}$ was used as a molecular weight marker. GelRed staining solution (Biotium) was added in gel and the gels were photographed using UV light and a Sony camera. Images were later used to score amplification products and set up the binary data.

\section{Scoring and data analysis of microsatellite markers}

Each amplification product was considered as an independent character (locus) and was identified by the name of the primer and the size of the DNA amplification product. The amplified fragments in each of the 16 gac accessions were scored manually for their presence (denoted as " 1 ") or absence (denoted as " 0 ") for each primer combination. Fragment size was compared to a molecular weight of the $50 \mathrm{bp}$ DNA ladder.

\section{Genetic distance and cluster analysis of SSR markers}

The binary data was used to generate a similarity index (matrix) using the method based on Nei and Li (1979) genetic distance value. Genetic similarity GS $=\frac{2 N a b}{N a+N b}$ where $N a b$ is the number of fragments shared by accession $a$ and $b$, $\mathrm{Na}$ is the number of fragments in accession $a$, and $N b$ is the number of fragments in accession $b$. For the analyses of genetic distances among populations, the similarity matrix was converted to a distance matrix, using formula $G D=1-G S$ or $G D=-\ln (G S)$ (Weising et al., 2005). This matrix was further employed to generate dendrogram using 
the unweighted pair group arithmetic average method (UPGMA).

Cluster analysis was carried out based on the SAHN-UPGMA method by using the Numerical Taxonomy System (NTSYSpc 2.1) software. To calculate $H_{E}$ (Expected heterozygosity), $H_{O}$ (Observed heterozygosity) and PIC (Polymorphism information contents) of genetic diversity for the SSR binary data, the Popgene software version 1.31 (Yeh and Boyle, 1997) was employed.

\section{Conclusion}

In conclusions, high genetic diversity was found among gac (M. cochinchinensis) accessions collected in Southern Vietnam. Combination of fruit-morphological with molecular markers such as microsatellite markers gives a good observation of genetic diversity of gac accessions. Where the genotypes are difficult to be identified by fruitmorphological markers because of their similar growing habit, fruit shape, fruit color, aril color, seed color and so on. However, these genotypes can be distinguished from one another by the use of SSR markers. Therefore, SSR markers could be useful molecular markers in gac genetic diversity and in large-scale breeding programs in future.

\section{Acknowledgements}

This project was supported by The National Foundation for Science and Technology Development (NAFOSTED), Vietnam (grant number 106-NN.03-2013.15). The authors acknowledge Professor Duong Tan Nhut at Tay Nguyen Institute of Biology for valuable advices. We are thankful to all colleagues for their assistance and support.

\section{References}

Behera T, Singh A, Staub JE (2008) Comparative analysis of genetic diversity in Indian bitter gourd (Momordica charantia L.) using RAPD and ISSR markers for developing crop improvement strategies. Sci Hort. 115(3): 209-217

Bharathi LK, John KJ (2013) Momordica genus in Asia: an overview. Springer

Bootprom N, Songsri P, Suriharn B, Chareonsap P, Sanitchon J, Lertrat K (2012) Molecular diversity among selected Momordica cochinchinensis (Lour.) Spreng accessions using RAPD markers. Sabrao J Breed Genet. 44(2): 406-417

Bootprom N, Songsri P, Suriharn B, Lomthaisong K, Lertrat K (2015) Genetics diversity based on agricultural traits and phytochemical contents in spiny bitter gourd (Momordica cochinchinensis (Lour.) Spreng). Sabrao J Breed Genet. 47(3): 278-290

Dey S, Singh A, Chandel D, Behera T (2006) Genetic diversity of bitter gourd (Momordica charantia L.) genotypes revealed by RAPD markers and agronomic traits. Sci Hort. 109(1): 21-28

Doldi ML, Vollmann J, Lelley T (1997) Genetic diversity in soybean as determined by RAPD and microsatellite analysis. Plant Breeding. 116(4): 331-335

Ganesh S, Thangavelu S (1995) Genetic divergence in sesame (Sesamum indicum). Madras Agric J. 82: 263-265
Guo D-L, Zhang J-P, Xue Y-M, Hou X-G (2012) Isolation and characterization of 10 SSR markers of Momordica charantia (Cucurbitaceae). Am J Bot. 99(5): 182-183

He G, Meng R, Newman M, Gao G, Pittman RN, Prakash CS (2003) Microsatellites as DNA markers in cultivated peanut (Arachis hypogaea L.). BMC Plant Biol. 3(1): 1-6

Ishida BK, Turner C, Chapman MH, McKeon TA (2004) Fatty acid and carotenoid composition of gac (Momordica cochinchinensis Spreng) fruit. J Agric Food Chem. 52(2): 274-279

Ispizua VN, Guma IR, Feingold S, Clausen AM (2007) Genetic diversity of potato landraces from northwestern Argentina assessed with simple sequence repeats (SSRs). Genet Resour Crop Evol. 54(8): 1833-1848

Isshiki S, Iwata N, Khan MMR (2008) ISSR variations in eggplant (Solanum melongena L.) and related Solanum species. Sci Hort. 117(3): 186-190

Jo MH, Ham IK, Moe KT, Kwon S-W, Lu F-H, Park Y-J, Kim WS, Won MK, Kim TI, Lee EM (2012) Classification of genetic variation in garlic (Allium sativum L.) using SSR markers. Aust J Crop Sci. 6(4): 625-631

Koornneef M (1990) Arabidopsis thaliana genetic map. In: Brien SJ (ed) Cold spring harbor laboratory press. Cold spring Harbor, New York, pp 694-697

Liu C (1997) Geographical distribution of genetic variation in Stylosanthes scabra revealed by RAPD analysis. Euphytica. 98(1-2): 21-27

Miah G, Rafii MY, Ismail MR, Puteh AB, Rahim HA, Islam KN, Latif MA (2013) A review of microsatellite markers and their applications in rice breeding programs to improve blast disease resistance. Int J Mol Sci. 14(11): 22499-22528

Nei M, Li WH (1979) Mathematical model for studying genetic variation in terms of restriction endonucleases. Proc Natl Acad Sci. 76(10): 5269-5273

Patil C, Baratakke R, Sandigwad A (2012) Development of a RAPD-based SCAR marker for sex identification in Momordica dioica Roxb. Isr J Plant Sci. 60(4): 457-465

Powell W, Morgante M, Andre C, Hanafey M, Vogel J, Tingey S, Rafalski A (1996) The comparison of RFLP, RAPD, AFLP and SSR (microsatellite) markers for germplasm analysis. Mol Breed. 2(3): 225-238

Pham TD, Bui TM, Werlemark G, Bui TC, Merker A, Carlsson AS (2009) A study of genetic diversity of sesame (Sesamum indicum L.) in Vietnam and Cambodia estimated by RAPD markers. Genet Resour Crop Evol. 56(5): 679-690

Rasul M, Hiramatsu M, Okubo H (2007) Genetic relatedness (diversity) and cultivar identification by randomly amplified polymorphic DNA (RAPD) markers in teasle gourd (Momordica dioica Roxb.). Sci Hort. 111(3): 271-279

Reiter RS, Young RM, Scolnik PA, Koncz C, Chua N, Schell J (1992) Genetic linkage of the Arabidopsis genome: methods for mapping with recombinant inbreds and Random Amplified Polymorphic DNAs (RAPDs). Methods in Arabidopsis research: 170-190

Salazar B, Laurentin H, Davila M, Castillo MA (2006) Reliability of the RAPD technique for germplasm analysis of sesame (Sesamum indicum L.) from Venezuela. Interciencia. 31(6): 456-460

Sanwal S, Yadav R, Rai N, Yadav D, Singh P (2007) Genetic diversity and interrelation analysis in sweet gourd (Momordica cochinchinensis) genotypes of Northeast India. Veg Sci. 34(1): 64-66 
Schaefer H, Renner SS (2010) A three-genome phylogeny of Momordica (Cucurbitaceae) suggests seven returns from dioecy to monoecy and recent long-distance dispersal to Asia. Mol Phylogenet Evol. 54(2): 553-560

Stankiewicz M, Gadamski G, Gawronski S (2001) Genetic variation and phylogenetic relationships of triazine resistant and triazine susceptible biotypes of Solanum nigrum analysis using RAPD markers. Weed Res. 41(4): 287-300

Tantasawat P, Trongchuen J, Prajongjai T, Jenweerawat S, Chaowiset W (2011) SSR analysis of soybean (Glycine max (L.) Merr.) genetic relationship and variety identification in Thailand. Aust J Crop Sci. 5(3): 283-290

Wang S-Z, Pan L, Hu K, Chen C-Y, Ding Y (2010) Development and characterization of polymorphic microsatellite markers in Momordica charantia (Cucurbitaceae). Am J Bot. 97(8): 75-78

Warwick SI, Gugel RK (2003) Genetic variation in the Crambe abyssinica-C. hispanica-C. glabrata complex. Genet Resour Crop Evol. 50(3): 291-305
Weising K, Nybom H, Wolff K, Kahl G (2005) Evaluation of molecular marker data. In: DNA fingerprinting in plant: Principles, methods, and applications. CRC Press, pp 207233

Wimalasiri D, Piva T, Urban S, Huynh T (2016) Morphological and genetic diversity of Momordica cochinchinensis (Cucurbitaceae) in Vietnam and Thailand. Genet Resour Crop Evol. 63(1): 19-33

Yeh FC, Boyle TJB (1997) Population genetic analysis of codominant and dominant markers and quantitative traits. Belgian J Bot. 129(2): 157-157

Zhao WG, Chung JW, Lee GA, Ma KH, Kim HH, Kim KT, Chung IM, Lee JK, Kim NS, Kim SM (2011) Molecular genetic diversity and population structure of a selected core set in garlic and its relatives using novel SSR markers. Plant Breeding. 130(1): 46-54

Zhou Y, Zhou C, Yao H, Liu Y, Tu R (2008) Application of ISSR markers in detection of genetic variation among Chinese yam (Dioscorea opposita Thunb) cultivars. Life Sci J. 5(4): 612 